\section{Treatment of foodborne botulism in current clinical toxicology: authors' reply}

\author{
Davide Lonati, 1 \\ Carlo Alessandro Locatelli, 1 \\ Lucia Fenicia,2 Fabrizio Anniballi,2 \\ Paolo Landri, ${ }^{3}$ Andrea Giampreti, 1 \\ Valeria Margherita Petrolini, ${ }^{1}$ \\ Sarah Vecchio, ${ }^{1}$ Luigi Manzo1 \\ 1Pavia Poison Center and National \\ Toxicology Information Centre Toxicology \\ Unit, IRCCS Maugeri Foundation and \\ University of Pavia; 2Department of \\ Veterinary Public Health and Food \\ Safety, National Reference Centre for \\ Botulism, Istituto Superiore di Sanità, \\ Roma; 3Intensive Care Unit, \\ S. Maria della Speranza Hospital, \\ Battipaglia, Italy
}

Dr. Zamani pointed out the role of the whole bowel irrigation (WBI) with polyethylene glycol as an appropriate adjunctive option of gastrointestinal decontamination in severe botulism poisoning. Secondly, the author underline the early administration of trivalent antitoxin as soon as clinical suspicion of botulism poisoning is made. ${ }^{1}$ However in the case described there are some considerations that need to be evaluated. ${ }^{2}$ First of all, regarding the gastrointestinal decontamination in severe botulism poisoned patient, all procedures aimed to remove spores and toxin from the gut should be applied. In details when post-pyloric decontamination with cathartic agents must be performed, sorbitol should be preferable than magnesium salts because the latter may exacerbate neuromuscular blockade. ${ }^{3}$ WBI may have a theoretical role in decontamination and it could be evaluated in severe poisoning. ${ }^{3}$ However, these procedures may be difficult and their efficacy may be reduced in the presence of drug- or toxin-induced ileus. ${ }^{4}$ In some cases prostigmine, which inhibits the enzymatic degradation of acetylcholine, appears to be useful in reversing ileus. ${ }^{5}$ In our case, the prolonged absence of peristalsis and the gas- tric stasis made cathartic agents administration difficult; in fact gastrointestinal decontamination with nasogastric tube, activated charcoal oral administration and intravenous prostigmine were performed to reduce the toxin absorption and to promote the gut peristalsis. About the timing of antidote administration, it should keep in mind that the aim of the antitoxin therapy consists in neutralizing the circulating toxin molecules still unbound to the nerve endings: this mechanism of action limits the involvement of new nerve endings, but cannot reverse the paralysis nor neutralize the toxins already bound to the nerve receptors. ${ }^{4}$ The clinical picture of our baby was severe still at admission (severe respiratory failure with hypoxemia and metabolic acidosis) and rapidly worsening consistent with the ingestion of a large dose of type A toxin, the most potent type of botulinum neurotoxins. In our case, trivalent antitoxin was administered about 10 hours after laboratory confirmation. Little age of the infant, the insidious onset of clinical manifestation, the rapid worsening of respiratory and neurological features and initial lack of specific history for a food source at hospital admission made the diagnostic suspicion difficult and delayed by differential diagnosis procedures (e.g. chest X-ray, electroencephalogram, cranial-computed tomography and magnetic resonance imaging scan, cerebrospinal analysis). Moreover when foodborne botulism was suspected, the antidote was immediately requested and obtained from the Health Ministry Stockpile after the laboratory confirmation was obtained. As Dr. Zamani correctly observed, an immediate antitoxin administration should be evaluated both in symptomatic patients and asymptomatic individuals recently exposed to a presumptive food source. ${ }^{1}$ In fact, the antitoxin should be administered also before the laboratory results, immediately as soon as clinical suspicion of botulism poisoning is suspected. ${ }^{4}$ In our case: i) a positive history for food consumption was not promptly reported on hospital admission, ii) the clinical suspicion for botulism poisoning was difficult and unfortunately hypothesized late and iii) antitoxin research was performed only after laboratory confirmation: these aspects made the diagnosis and the
Correspondence: Davide Lonati, Pavia Poison Center and National Toxicology Information Centre - Toxicology Unit, IRCCS Maugeri Foundation and University of Pavia, via Salvatore Maugeri, 10 - 27100 Pavia, Italy.

Tel. +39.0382.26261 - Fax: +39.0382 .24605$

E-mail: davide.lonati@fsm.it

Key words: foodborne botulism, clinical toxicology.

Received for publication: 20 July 2012 .

Accepted for publication: 20 July 2012 .

This work is licensed under a Creative Commons Attribution NonCommercial 3.0 License (CC BYNC 3.0).

(C) Copyright D. Lonati et al., 2012

Licensee PAGEPress, Italy

Pediatric Reports 2012; 4:e27

doi:10.4081/pr.2012.e27

treatment of this case of severe foodborne botulism complicated and not as timely and prompt as theoretically desired.

\section{References}

1. Zamani N. Treatment of foodborne botulism in current clinical toxicology. Pediatr Rep 2012;4:e22.

2. Lonati D, Locatelli CA, Fenicia L, et al. Fatal course of foodborne botulism in an eight-month old infant. Pediatr Rep 2011; 3:e31.

3. Goldfrank LR, Flomenbaum NE. Botulism. In: Flomenbaum NE, Goldfrank LR, Hoffman RS, et al. Goldfrank's toxicologic emergencies, 8th ed. New York City: McGraw-Hill; 2006. pp 715-727.

4. Lonati D, Rossetto 0, Fenicia L, Locatelli C. Botulism. In: Ballantyne B, Marrs T, Syversen T. General and applied toxicology, 3th ed. Chicester, UK: John Wiley \& Sons Ltd; 2009. pp 3555-3579.

5. Isbister GK, Oakley P, Whyte I, et al. Treatment of anticholinergic-induced ileus with neostigmine. Ann Emerg Med 2001;38: $689-93$ 